\title{
Expression of claudin-11 in a rat model of varicocele and its effects on the blood-testis barrier
}

\author{
JIANGANG PAN, ZHIRONG ZHU, GANG XU, LILI NIU, LIHANG YU, ZHENGANG LUO and JIAJUN YAN \\ Department of Urology, Shaoxing People's Hospital (Shaoxing Hospital of Zhejiang University School of Medicine), \\ Shaoxing, Zhejiang 312000, P.R. China
}

Received March 19, 2018; Accepted October 5, 2018

DOI: $10.3892 / \mathrm{mmr} .2018 .9603$

\begin{abstract}
Varicocele (VC) is an abnormal tortuosity and venous distension of the pampiniform plexus in the spermatic cord. VC is the most common surgically correctable cause of male infertility. The purpose of the present study was to investigate the effects of $\mathrm{VC}$ on the tight junctions and the blood-testis barrier (BTB) of Sertoli cells in the bilateral testes of rats. A model of VC was established by left renal vein narrowing in Sprague-Dawley rats; control rats underwent dissection of the vein without narrowing. The bilateral testes were harvested at 4, 6 and 8 weeks after the operation. The relative expression of claudin-11 and transforming growth factor (TGF)- $\beta$ in the testis was determined by reverse transcription-polymerase chain reaction analysis and immunohistochemistry (IHC). The expression level of claudin-11 was prominently downregulated in the VC model group compared with the control group, while the level of TGF- $\beta$ in the testes was higher in the VC group. IHC examination demonstrated that $\mathrm{VC}$ led to destruction of the integrity of the BTB, and the degree of destruction increased with time. Furthermore, it was also observed that unilateral VC affected contralateral testicular function. In conclusion, the present study partially explained the molecular mechanisms underlying the pathogenesis of $\mathrm{VC}$ and provided grounds for further research into the treatment of male infertility.
\end{abstract}

\section{Introduction}

Varicocele (VC) is considered to be the main cause of male infertility (1). It has been demonstrated that VCs adversely affect sperm quality $(2,3)$, sperm function $(4,5)$, testicular histology $(6,7)$ and reproductive hormones (8). VCs are

Correspondence to: Dr Jiangang Pan, Department of Urology, Shaoxing People's Hospital (Shaoxing Hospital of Zhejiang University School of Medicine), 568 Zhongxing Road, Shaoxing, Zhejiang 312000, P.R. China

E-mail: pjgwcx@163.com

Key words: varicocele, claudin-11, blood-testis barrier considered to exert a negative effect on the function of Sertoli and Leydig cells. The imbalanced hypothalamus-pituitary-gonadal axis ultimately affects spermatogenesis due to the decreased testosterone levels (9).

The blood-testis barrier (BTB) consists of junctional and cytoskeletal structures, and it is one of the tightest blood-tissue barriers in mammals $(10,11)$. Tight junctions (TJs), gap junctions (GJs) and desmosomes form this barrier. Claudins are proteins that interact with cytoskeletal proteins and are important components of tight junctions (12). A variety of claudins are expressed in rodent testes (13) and several participate in the formation of the BTB. Claudin-11 is detected at day 12 post-coitus (14), and claudin-11 knockout is not lethal in mice, but they are sterile (13). Claudin-11/Sertoli cells exhibit a unique phenotype by loss of tight junction connection integrity, leading to loss of the epithelial phenotype (15). The BTB has a crucial role in the process of spermatogenesis, and claudin-11 is an important tight junction protein expressed by Sertoli cells that is involved in the formation of the BTB. Abnormal expression of claudin-11 affects the function of the BTB; however, precisely how VC affects claudin-11 expression resulting in further alterations of the BTB remains unknown.

Recent studies have demonstrated that transforming growth factor (TGF)- $\beta$ secreted by testicular cells can alter the tightness of the tight junctions via the $\mathrm{p} 38$-mitogen-activated protein kinase pathway $(16,17)$. Therefore, it would be interesting to elucidate whether TGF- $\beta$ is involved in the pathogenesis of $\mathrm{VC}$, as preventing the testicular cells from synthesizing TGF- $\beta$ may affect the tightness of the junctions between supporting cells and prevent spermatogenesis. To address these questions, a VC rat model was established and the molecular and histological changes in the testes were observed, in order to provide evidence on the pathogenic mechanisms of $\mathrm{VC}$ and determine the potential value in development of non-hormonal male contraceptives.

To the best of our knowledge, this study is the first to measure claudin-11 expression levels in ipsilateral and contralateral testicular Sertoli cells in a VC model, and to investigate its characteristics over time and the effects on BTB function from the perspective of $\mathrm{VC}$-induced male infertility. The research results may further establish the inclusion of claudin-11 in BTB-associated studies and provide a basis for the development of potential non-hormonal male contraceptives. 


\section{Materials and methods}

Animals and groups. A total of 32 mature male (12 weeks) Sprague-Dawley rats, weighing $200 \pm 20 \mathrm{~g}$, were purchased from the Shanghai Laboratory Animal Centre (Shanghai, China). The animal experiments were performed in accordance with the guidelines of the ethics committee of Zhejiang University, and the animals were handled according to the Guide for the Care and Use of Laboratory Animals published by the US National Institutes of Health (18). The experiment was approved by the Animal Care and Use Committee of Zhejiang University (ZDSX2017-0012).

The rats were randomly divided into the following 7 groups: Normal control group (NC), 4 weeks VC (4W-VC), 4 weeks sham surgery (4W-SHAM), 6 weeks VC $(6 \mathrm{~W}-\mathrm{VC})$, 6 weeks sham surgery $(6 \mathrm{~W}-\mathrm{SHAM}), 8$ weeks VC $(8 \mathrm{~W}-\mathrm{VC})$ and 8 weeks sham surgery ( $8 \mathrm{~W}-\mathrm{SHAM})$. The VC model was established by partial ligation of the left renal vein according to the method described by Hurt et al $(19,20)$. Briefly, $1 \%$ pentobarbital sodium $(35 \mathrm{mg} / \mathrm{kg})$ was administered via intraperitoneal injection to induce anaesthesia. The left renal vein was isolated at its junction with the inferior vena cava, and a $0.8-\mathrm{mm}$ metal ligature wire was placed to narrow the left renal vein to half of its original diameter. The branch veins of the spermatic vein were also ligated. Successful modelling criteria included: i) Diameter of the spermatic vein $>1 \mathrm{~mm}$; and ii) no difference in size between the left and right kidneys. Isolation of the left renal vein with no ligation was performed in the sham surgery control group. The rats were euthanized by cervical dislocation following anaesthesia with intraperitoneal injection of $10 \%$ chloral hydrate $(200 \mathrm{mg} / \mathrm{kg})$. The testicles were collected at 4, 6 and 8 weeks after model establishment and weighed. The structure of the spermatic vein was observed under a microscope, and the diameter was measured with scales.

Reverse transcription-quantitative polymerase chain reaction (RT-qPCR) analysis. Total RNA was extracted from testicular tissues using TRIzol ${ }^{\circledR}$ reagent (Invitrogen; Thermo Fisher Scientific Inc., Waltham, MA, USA). RNA quantity and quality were tested with NanoDrop 1000 (NanoDrop; Thermo Fisher Scientific Inc.) and gel electrophoresis. The primers (Table I) for qPCR were designed using Primer Premier 5.0 software and synthesized by Generay Biotech Co., Ltd. (Shanghai, China). cDNA synthesis was performed using the ReverTra Ace ${ }^{\circledR}$ qPCR RT kit (Toyobo Life Science, Osaka, Japan) according to the manufacturer's protocol. The reverse transcription reaction was performed at $65^{\circ} \mathrm{C}$ for $5 \mathrm{~min}, 37^{\circ} \mathrm{C}$ for $15 \mathrm{~min}$ and $98^{\circ} \mathrm{C}$ for $5 \mathrm{~min}$. qPCR was performed using the KAPA SYBR Green Supermix PCR kit (Kapa Biosystems; Roche Diagnostics, Indianapolis, IN, USA) according to the kit protocol, with AriaMx Real-Time PCR System (Agilent Technologies, Inc., Santa Clara, CA, USA). The thermocycling conditions were as follows: $95^{\circ} \mathrm{C}$ for $30 \mathrm{sec}$, followed by 40 cycles of $95^{\circ} \mathrm{C}$ for $20 \mathrm{sec}$ and $61^{\circ} \mathrm{C}$ for $30 \mathrm{sec}$. The relative expression of different genes was determined using the $2^{-\Delta \Delta \mathrm{Cq}}$ algorithm (21).

Immunohistochemistry (IHC). Testicular tissues were fixed with $4 \%$ paraformaldehyde for $24 \mathrm{~h}$ at $4^{\circ} \mathrm{C}$, embedded in paraffin and cut into $5 \mu \mathrm{m}$ thick sections by Servicebio (Shanghai, China). Sections were blocked in 5\% BSA for $1.5 \mathrm{~h}$ at $37^{\circ} \mathrm{C}$ (Beyotime Institute of Biotechnology, Shanghai, China). The antibodies were purchased from Abcam (Cambridge, UK) and included anti-TGF- $\beta 1$ (cat. no. ab9758; 1:1,000), anti-claudin-11 (cat. no. ab7474; 1:1,000) and horseradish peroxidase-conjugated secondary antibody (cat. no. ab6721; 1:1,000). Detailed experimental steps were performed as described by Jasinski-Bergner et al (22). Scoring of the expression of claudin- 11 and TGF- $\beta 1$ was performed by two independent pathologists as described by Sewify et al (23).

Statistical analysis. All data are expressed as the mean \pm standard deviation unless otherwise specified. GraphPad Prism 5 (GraphPad Software, Inc., La Jolla, CA, USA) was used to perform statistical analysis for all results. Significance between groups was evaluated by one-way analysis of variance. Each experiment of RT-qPCR and IHC was performed three times. $\mathrm{P}<0.05$ was considered to indicate a statistically significant difference.

\section{Results}

$V C$ modelling. The diameter of the spermatic vein in the $\mathrm{VC}$ model group was significantly larger compared with that in the NC group, and further increased with time $(\mathrm{P}<0.001$; Fig. 1). The left testicular weight in the $6 \mathrm{~W}-\mathrm{VC}$ group was significantly decreased compared with the right testicular weight $(1.36 \pm 0.05$ vs. $1.46 \pm 0.08 \mathrm{~g}$, respectively; $\mathrm{P}<0.05)$, and the left testicular weight in the $8 \mathrm{~W}-\mathrm{VC}$ group was significantly decreased compared with the right testicular weight $(1.35 \pm 0.05$ vs. $1.50 \pm 0.06$ g, respectively; $\mathrm{P}<0.001$; Fig. 2$)$. These results indicated successful construction of the VC model in rats.

$R T-q P C R$ of claudin-11. There was no statistically significant difference in mRNA levels of claudin-11 between the SHAM and VC groups at 4 weeks. However, the expression of claudin-11 was significantly downregulated in $6 \mathrm{~W}-\mathrm{VC}-\mathrm{L}$ compared with 6W-SHAM-L $(\mathrm{P}<0.05)$. In addition, the expression of the claudin-11 was more significantly downregulated in 8W-VC-L compared with the 8W-SHAM-L $(\mathrm{P}<0.001)$. Notably, there was a statistically significant difference between $8 \mathrm{~W}-\mathrm{VC}-\mathrm{L}$ and $8 \mathrm{~W}-\mathrm{VC}-\mathrm{R}$, and between $8 \mathrm{~W}-\mathrm{SHAM}-\mathrm{R}$ and 8W-VC-R (P<0.01; Fig. 3).

IHC of claudin-11 and TGF- $\beta$. The expression of claudin-11 was further analysed in 32 stained paraffin-embedded tissue samples of rat testicular tissue (Fig. 4). The expression of claudin-11 was downregulated in the VC model compared with the NC group $(\mathrm{P}<0.01)$, and there was a significant difference between the diseased side (left) and the healthy side (right). The expression level of TGF- $\beta$ in the VC model group was significantly higher compared with that in the SHAM group at week $6(\mathrm{P}<0.01)$, and more significantly increased at week $8(\mathrm{P}<0.001)$. Compared with the normal side (VC-R), the operated side (VC-L) also exhibited significantly higher expression of TGF- $\beta$ in all three time points $(\mathrm{P}<0.05$; Fig. 5). 
Table I.Primer sequences used in the reverse transcription-quantitative polymerase chain reaction.

\begin{tabular}{lcc}
\hline Primer & Direction & \multicolumn{1}{c}{ Sequence $\left(5^{\prime} \rightarrow 3^{\prime}\right)$} \\
\hline Claudin-11 & F & TTAGACATGGGCACTCTTGG \\
& R & ATGGTAGCCACTTGCCTTC \\
GAPDH & F & CAAGTTCAACGGCACAGTCAAG \\
& R & ACATACTCAGCACCAGCATCAC \\
\hline
\end{tabular}

F, forward; R, reverse.

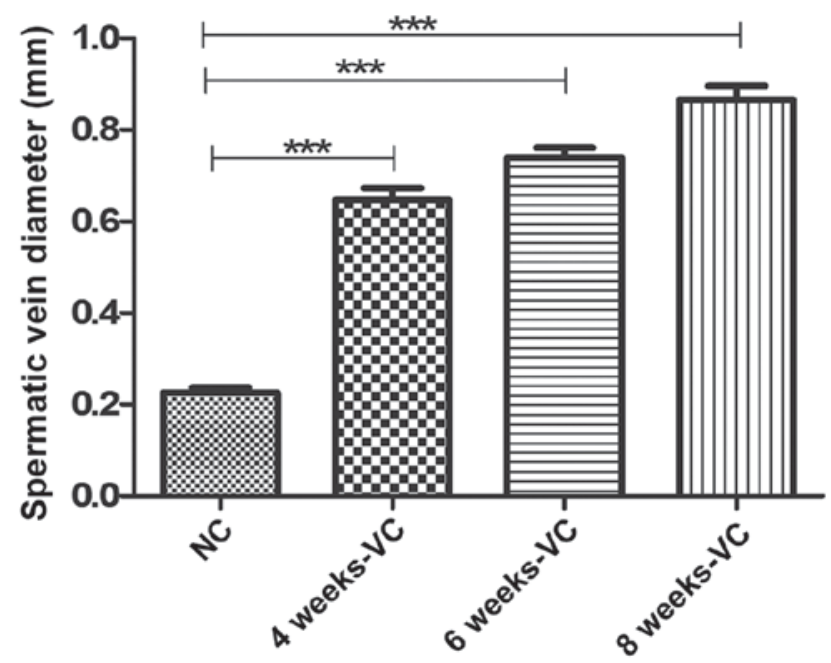

Figure 1. Spermatic vein diameter of different groups. The spermatic vein diameter was significantly higher in the $\mathrm{VC}$ model groups compared with the NC group. ${ }^{* * *} \mathrm{P}<0.001$. NC, normal control group; $\mathrm{VC}$, varicocele.

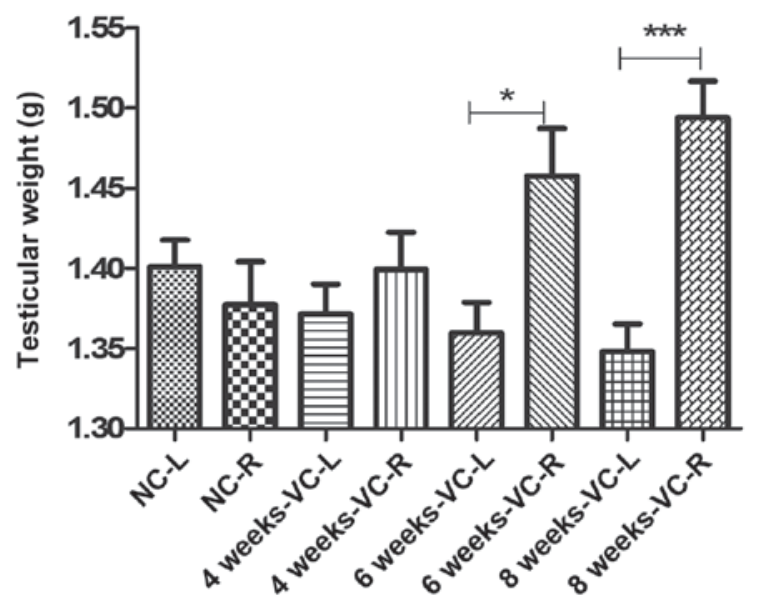

Figure 2. Testicular weight was significantly higher on the right healthy side compared with the left diseased side. ${ }^{*} \mathrm{P}<0.05 ;{ }^{* * *} \mathrm{P}<0.001$. L, left; $\mathrm{R}$, right; $\mathrm{NC}$, normal control group; $\mathrm{VC}$, varicocele.

\section{Discussion}

In the present study, a VC rat model was established to study the molecular and histological changes in the testes in the early phases of VC development. The pathogenic process was initiated by disruption of the BTB.

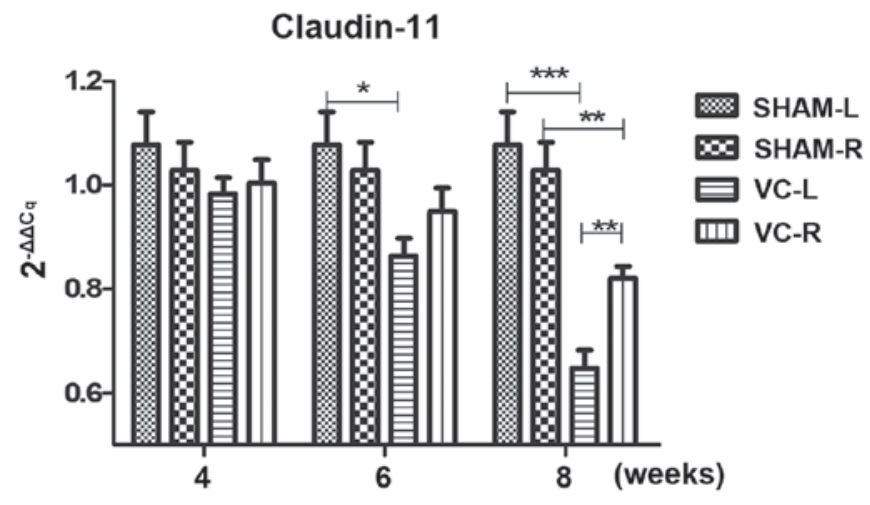

Figure 3. Expression of claudin-11 at the mRNA level. ${ }^{*} \mathrm{P}<0.05 ;{ }^{* *} \mathrm{P}<0.01$; ${ }^{* * *} \mathrm{P}<0.001$. SHAM, sham surgery control group; L, left diseased side; $\mathrm{R}$, right healthy side; VC, varicocele.

As rats are commonly used in BTB disruption studies $(24,25)$, a classic VC rat model was established to mimic damage to the BTB in humans, and determine the effect in claudin-11 in the variceal and contralateral testis at different time points postoperatively (12).

RT-PCR revealed that the expression of claudin-11 was downregulated in $\mathrm{VC}$ rats at 6 and 8 weeks, and the diseased side was more significantly affected compared with the healthy side at week 8 . The same trends were observed on IHC examination. In addition, the expression of claudin-11 decreased gradually over time.

The histopathological examination revealed increasing disruption of the integrity of the BTB over time, and unilateral $\mathrm{VC}$ also affected contralateral testicular function. Oh et al (26) reported that an increase in the levels of pro-inflammatory cytokines may be caused by deregulation of claudin-11 expression in the Sertoli cells of VC testes, leading to alterations in the permeability of the BTB and immunological barriers to normal spermatogenesis. The results of previous studies $(24,27)$ suggest that VC-induced male infertility is mediated by damage to the BTB.

The results of the current study also demonstrated that the expression of TGF- $\beta$ increased in VC rats, which was not limited to the diseased side, but also gradually affected the healthy side over time. TGF- $\beta$ was reported to be associated with fibrosis of the seminiferous tubules and disruption of spermatogenesis. In the testis, TGF- $\beta$ is known to stimulate collagen and fibronectin, further triggering the production of extracellular matrix (28). During puberty, the expression of TGF- $\beta$ is regulated by hormonal influences and is involved in steroidogenesis and spermatogenesis $(29,30)$.

In conclusion, the present study partially explained the histopathological and molecular mechanisms underlying the pathogenesis of $\mathrm{VC}$, and the findings may be useful in the treatment of male infertility.

\section{Acknowledgements}

The authors acknowledge the valuable suggestions and technical assistance provided by the laboratory staff of the Department of Urology at Shaoxing People's Hospital (Shaoxing, China). 


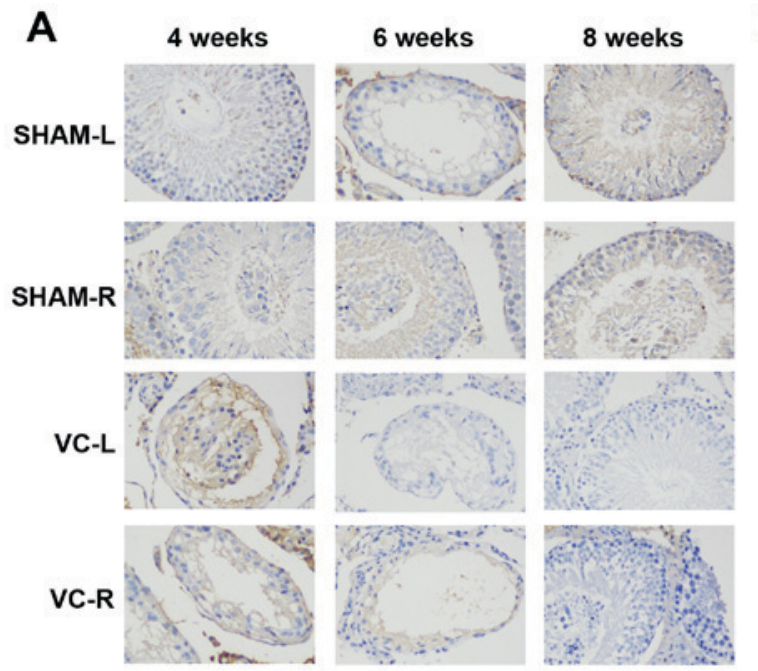

B

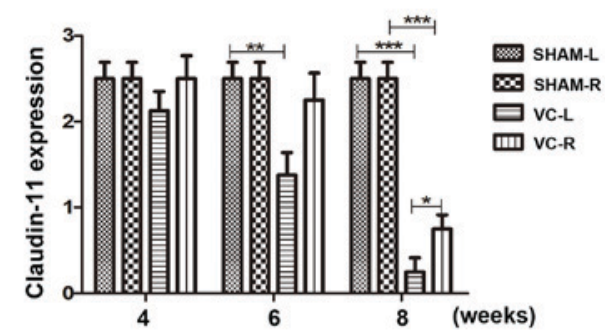

Figure 4. Claudin-11 expression in rat testicular tissue. (A) Immunohistochemical examination of claudin-11 expression in Sprague-Dawley rat testicular tissue. (B) Scoring of the expression of claudin-11. ${ }^{*} \mathrm{P}<0.05 ;{ }^{* *} \mathrm{P}<0.01 ;{ }^{* * *} \mathrm{P}<0.001$. SHAM, sham surgery control group; L, left diseased side; R, right healthy side; VC, varicocele.
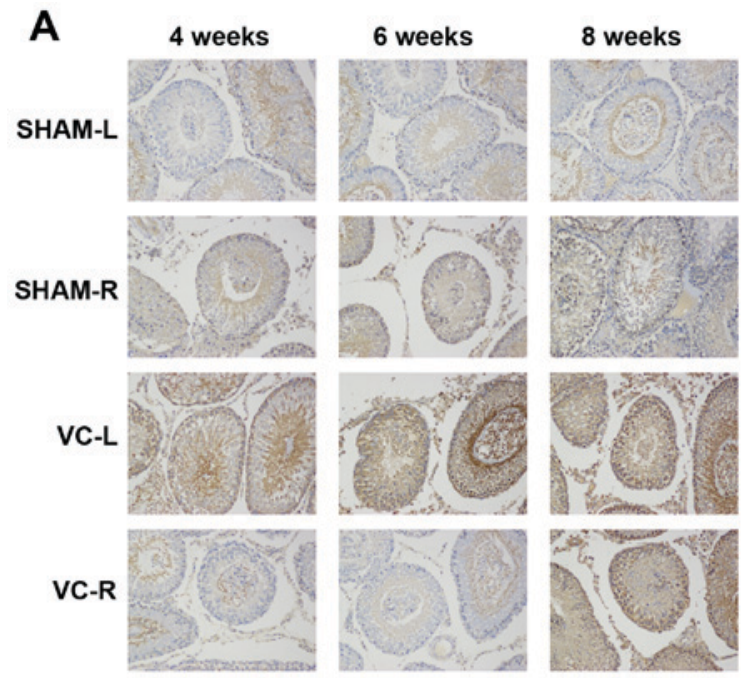

B

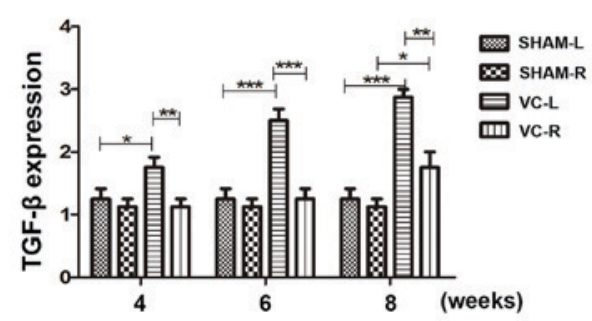

Figure 5. TGF- $\beta$ expression in rat testicular tissue. (A) Immunohistochemical examination of TGF- $\beta$ in Sprague-Dawley rat testicular tissue. (B) Scoring of the expression of TGF- $\beta .{ }^{*} \mathrm{P}<0.05 ;{ }^{* * *} \mathrm{P}<0.01 ;{ }^{* * * *} \mathrm{P}<0.001$. TGF- $\beta$ was more highly expressed in the VC-L compared with all other groups at all three time points. SHAM, sham surgery control group; L, left diseased side; R, right healthy side; VC, varicocele; TGF- $\beta$, transforming growth factor- $\beta$.

\section{Funding}

The present study was funded by the Shaoxing Municipal Bureau of Science and Technology in China (grant no. 2015B70054).

\section{Availability of data and materials}

The datasets used and/or analyzed during the present study are available from the corresponding author on reasonable request.

\section{Authors' contributions}

$\mathrm{JP}$ was involved in all aspects of the research. ZZ and JY were involved in the animal experiments and data analysis. GX, LN, LY and ZGL were involved in RT-qPCR and IHC. All the authors have read and approved the final version of this manuscript.

\section{Ethics approval and consent to participate}

The animal experiments were performed in accordance with the guidelines of the Ethics Committee of Zhejiang University (Shaoxing, China), and the animals were handled according to the Guide for the Care and Use of Laboratory Animals published by the US National Institutes of Health. The experiment was approved by the Animal Care and Use Committee of Zhejiang University (ZDSX2017-0012).

\section{Patient consent for publication}

Not applicable. 


\section{Competing interests}

The authors declare that they have no competing interests.

\section{References}

1. Dubin L and Amelar RD: Etiologic factors in 1294 consecutive cases of male infertility. Fertil Steril 22: 469-474, 1971.

2. Damsgaard J, Joensen UN, Carlsen E, Erenpreiss J, Blomberg Jensen M, Matulevicius V,Zilaitiene B, Olesen IA, Perheentupa A, Punab M, et al: Varicocele is associated with impaired semen quality and reproductive hormone Levels: A study of 7035 healthy young men from six european countries. Eur Urol 70 1019-1029, 2016.

3. The influence of varicocele on parameters of fertility in a large group of men presenting to infertility clinics. World Health Organization. Fertil Steril 57: 1289-1293, 1992.

4. Wang YJ, Zhang RQ, Lin YJ, Zhang RG and Zhang WL: Relationship between varicocele and sperm DNA damage and the effect of varicocele repair: A meta-analysis. Reprod Biomed Online 25: 307-314, 2012

5. Vigil P, Wöhler C, Bustos-Obregón E, Comhaire F and Morales P: Assessment of sperm function in fertile and infertile men. Andrologia 26: 55-60, 1994.

6. Abdelrahim F, Mostafa A, Hamdy A, Mabrouk M, el-Kholy M and Hassan O: Testicular morphology and function in varicocele patients: Pre-operative and post-operative histopathology. Br J Urol 72: 643-647, 1993

7. Etriby A, Girgis SM, Hefnawy H and Ibrahim AA: Testicular changes in subfertile males with varicocele. Fertil Steril 18 666-671, 1967.

8. Cayan S, Kadioglu A, Orhan I, Kandirali E, Tefekli A and Tellaloglu S: The effect of microsurgical varicocelectomy on serum follicle stimulating hormone, testosterone and free testosterone levels in infertile men with varicocele. BJU Int 84 1046-1049, 1999.

9. Pastuszak AW and Wang R: Varicocele and testicular function. Asian J Androl 17: 659-667, 2015.

10. Cheng CY and Mruk DD: The blood-testis barrier and its implications for male contraception. Pharmacol Rev 64: 16-64, 2012.

11. Franca LR, Auharek SA, Hess RA, Dufour JM and Hinton BT: Blood-tissue barriers: Morphofunctional and immunological aspects of the blood-testis and blood-epididymal barriers. Adv Exp Med Biol 763: 237-259, 2012.

12. Morrow CM, Mruk D, Cheng CY and Hess RA: Claudin and occludin expression and function in the seminiferous epithelium. Philos Trans R Soc Lond B Biol Sci 365: 1679-1696, 2010.

13. Morita K, Sasaki H, Fujimoto K, Furuse M and Tsukita S: Claudin-11/OSP-based tight junctions of myelin sheaths in brain and Sertoli cells in testis. J Cell Biol 145: 579-588, 1999.

14. Hellani A, Ji J, Mauduit C, Deschildre C, Tabone E and Benahmed $\mathrm{M}$ : Developmental and hormonal regulation of the expression of oligodendrocyte-specific protein/claudin 11 in mouse testis. Endocrinology 141: 3012-3019, 2000.

15. Mazaud-Guittot S, Meugnier E, Pesenti S, Wu X, Vidal H, Gow A and Le Magueresse-Battistoni B: Claudin 11 deficiency in mice results in loss of the Sertoli cell epithelial phenotype in the testis. Biol Reprod 82: 202-213, 2010.
16. Tossetta G, Paolinelli F, Avellini C, Salvolini E, Ciarmela P, Lorenzi T, Emanuelli M, Toti P, Giuliante R, Gesuita R, et al: IL- $1 \beta$ and TGF- $\beta$ weaken the placental barrier through destruction of tight junctions: An in vivo and in vitro study. Placenta 35: 509-516, 2014.

17. Rachakonda G, Vu T, Jin L, Samanta D and Datta PK: Role of TGF- $\beta$-induced Claudin-4 expression through c-Jun signaling in non-small cell lung cancer. Cell Signal 28: 1537-1544, 2016.

18. National Research Council: Guide for the care and use of laboratory animals. 8th edition. Washington (DC), National Academies Press (US), 2011

19. Hurt GS, Howards SS and Turner TT: The effects of unilateral, experimental varicocele are not mediated through the ipsilateral testis. J Androl 8: 403-408, 1987.

20. Hurt GS, Howards SS and Turner TT: Repair of experimental varicoceles in the rat. Long-term effects on testicular blood flow and temperature and cauda epididymidal sperm concentration and motility. J Androl 7: 271-276, 1986.

21. Livak KJ and Schmittgen TD: Analysis of relative gene expression data using real-time quantitative PCR and the 2(-Delta Delta C(T)) method. Methods 25: 402-408, 2001.

22. Jasinski-Bergner S, Büttner M, Quandt D, Seliger B and Kielstein H: Adiponectin and its receptors are differentially expressed in human tissues and cell lines of distinct origin. Obes Facts 10: 569-583, 2017.

23. Sewify EM, Afifi OA, Mosad E, Zaki AH and El Gammal SA: Cyclin D1 amplification in multiple myeloma is associated with multidrug resistance expression. Clin Lymphoma Myeloma Leuk 14: 215-222, 2014

24. Ha HK, Park HJ and Park NC: Expression of E-cadherin and $\alpha$-catenin in a varicocele-induced infertility rat model. Asian $\mathrm{J}$ Androl 13: 470-475, 2011.

25. Liu J, Ding D and Liu J: Varicocele-caused progressive damage in bilateral testis and sertoli cell-only syndrome in homolateral testis in rats. Med Sci Monit 20: 1931-1936, 2014.

26. Oh YS, Jo NH, Park JK and Gye MC: Changes in inflammatory cytokines accompany deregulation of claudin-11, resulting in inter-sertoli tight junctions in varicocele rat testes. J Urol 196: 1303-1312, 2016

27. Koksal IT, Ishak Y, Usta M, Danisman A, Guntekin E, Bassorgun IC and Ciftcioglu A: Varicocele-induced testicular dysfunction may be associated with disruption of blood-testis barrier. Arch Androl 53: 43-48, 2007.

28. Skinner MK: Cell-cell interactions in the testis. Endocr Rev 12: 45-77, 1991

29. Kimelman D: Peptide growth factors and the regulation of early amphibian development. Biochim Biophys Acta 1155: 227-237, 1993.

30. Dobashi M, Fujisawa M, Yamazaki T, Okada H and Kamidono S: Distribution of intracellular and extracellular expression of transforming growth factor-beta1 (TGF-beta1) in human testis and their association with spermatogenesis. Asian J Androl 4: 105-109, 2002.

This work is licensed under a Creative Commons Attribution-NonCommercial-NoDerivatives 4.0 International (CC BY-NC-ND 4.0) License. 